\title{
Envelhecimento e Longevidade no Rio Grande do Sul: um perfil histórico, étnico e de morbi-mortalidade dos idosos
}

Longevity and aging in Rio Grande do Sul state: a hystorical, ethnic and morbi-mortality profile

of elderly people

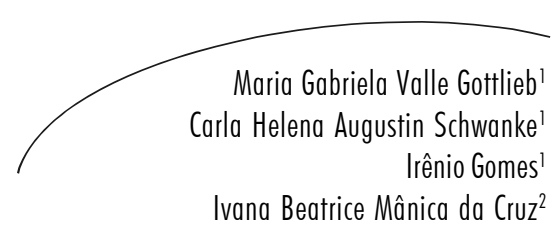

Resumo

O Estado Rio Grande do Sul apresenta uma grande diversidade étnica e cultural na sua população. Entretanto, pouco se sabe sobre o perfil genético desta população em relação às doenças crônicas não-transmissíveis (DCNT) e o do padrão de herança de acordo com a origem étnica. Fatores como etnia e composição genética, em conjunto com a Reforma Sanitária brasileira e com o estilo de vida, têm possivelmente contribuído de forma substancial para o aumento da expectativa média de vida ao nascer e da longevidade dos gaúchos. A população do Rio Grande do Sul tem apresentado um acelerado processo de envelhecimento populacional e com um padrão diferenciado de morbi-mortalidade para as faixas etárias acima de 60 anos. O aumento da longevidade da população trouxe consigo um aumento não somente da incidência e prevalência, mas também da mortalidade por DCNT, tais como doenças cardiovasculares e neoplasias. Por isso, as políticas públicas de saúde precisam contemplar as peculiaridades étnicas, culturais e biológicas para que a população possa envelhecer com qualidade de vida. É dentro desse contexto que o presente artigo pretende contribuir na discussão do processo de envelhecimento populacional do Rio Grande do Sul.

\section{Abstract}

Rio Grande do Sul state's population has great ethnic and cultural diversity. However, knowledge on the genetic profile of this population concerning chronic non-communicable diseases (NCDs) and the pattern of inheritance related to ethnic origin is poor. Ethnicity and genetic background, associated with the Brazilian sanitary reform and Brazilian lifestyle, contributed a lot to the increase

\footnotetext{
Programa de Pós-graduação em Gerontologia Biomédica, Instituto de Geriatria e Gerontologia. Pontifícia Universidade Católica do Rio Grande do Sul. Porto Alegre, RS, Brasil.

2 Departamento de Morfologia, Centro de Ciências da Saúde. Laboratório de Biogenômica, Universidade Federal de Santa Maria. Santa Maria, RS, Brasil.
}

\author{
Palavras-chave: \\ Envelhecimento. \\ Longevidade. Etnia. \\ Demografia. \\ Epidemiologia. Imigração. \\ Doenças Crônicas.
}

\footnotetext{
Correspondência / Correspondence

Maria Gabriela Valle Gottlieb

Instituto de Geriatria e Gerontologia, Programa de Pós-graduação em Gerontologia Biomédica

Pontifícia Universidade Católica do Rio Grande do Sul

Av. Ipiranga, 6690-219

90610-000. Porto Alegre RS-Brasil

E-mail: maria.gottlieb@pucrs.br
} 
in average life expectancy at birth, and longevity of that population. Thus, the population of Rio Grande do Sul presents an accelerated aging process, with a distinct pattern of morbidity and mortality for the elderly (aged 60 years or more). The increased longevity of this population increased not only the incidence and prevalence, but also the mortality from NCDs such as cardiovascular diseases and cancer. Therefore, public health policies must address ethnic, cultural and biological characteristics to promote aging with quality of life. In this context this paper aims to contribute to the discussion about the aging process in Rio Grande do Sul state, Brazil.
Key words: Aging. Longevity. Ethnicity. Demography. Epidemiology. Immigration. Chronic Diseases.

\section{INTRODUÇÃO}

A transição demográfica, fator preponderante para o envelhecimento populacional, fenômeno que atingiu países desenvolvidos no final do século XIX e ao longo do XX, está sendo observada também em países em desenvolvimento como o Brasil. Entretanto, o fenômeno no Brasil é bastante diferenciado do observado em países desenvolvidos, onde o envelhecimento populacional ocorreu dentro de um contexto socioeconômico favorável.

No Brasil esse processo está ocorrendo em ritmo acelerado, o que leva a dificuldades na realização de ajustes e expansão dos sistemas sociais relacionados com a atenção à pessoa idosa. ${ }^{1}$ Outra questão importante que dificulta a agenda $\mathrm{da}$ adaptação social ao crescente número de idosos diz respeito à grande heterogeneidade das regiões brasileiras em relação ao processo de envelhecimento.

De modo geral, o processo de envelhecimento, independentemente dos fatores étnicos, sociais e culturais inerentes a cada população, está associado a uma maior probabilidade de acometimento por doenças crônicas não-transmissíveis (DCNT). O processo de envelhecimento normal envolve alterações desde o nível molecular, passando pelo morfofisiológico até o funcional. Estas alterações estão associadas à própria idade, e também se originam do acúmulo de danos, ao longo da vida, causados sobretudo pela interação entre fatores genéticos e hábitos não saudáveis, como uma dieta desbalanceada, tabagismo, etilismo e sedentarismo.
Um estilo de vida inadequado acaba aumentando a ineficiência metabólica, que contribui substancialmente para a quebra $\mathrm{da}$ homeostasia corporal. Tal fato, lentamente, torna o indivíduo mais suscetível a lesões orgânicas, culminando no desencadeamento de DCNT. ${ }^{2}$ Nesse caso, o Rio Grande do Sul (RS), é um dos estados com maior prevalência e mortalidade por DCNT, como câncer de mama, próstata e doenças cardiovasculares (DCV). Essas evidências levantam a hipótese de que exista, além de componentes genéticos predisponentes a uma maior probabilidade de desenvolver alguma DCNT (herdados, advindos de um histórico multiétnico), fatores culturais associados, como o hábito alimentar peculiar dessa região.

Esta revisão está focada na dinâmica do envelhecimento e longevidade do estado do RS, por ser um dos estados com maior índice de desenvolvimento humano, maior expectativa de vida e proporção no número de idosos da população. Assim, o presente artigo teve o objetivo de avaliar o processo de envelhecimento e o incremento da longevidade no RS sob uma ótica, histórica, étnica, cultural e de saúde.

\section{METODOLOGIA}

Foi realizada revisão da literatura através da identificação, leitura e síntese de artigos indexados nas bases Medline e LILACS. Adicionalmente, foram consultados livros de Geriatria, Gerontologia, história da povoação sul-americana e do Rio Grande do Sul (RS) da Biblioteca Central da Pontifícia Universidade Católica do Rio 
Grande do Sul (PUCRS) e e-books, além do banco de dissertações e teses da CAPES. Para tanto, foram utilizados os seguintes termos: longevity, aging, ethnicity, demography, epidemiology, immigration, chronic diseases e seus respectivos correspondentes em português. Também foram acessadas as bases de dados do IBGE e do DATASUS, para levantamento das causas de óbitos e expectativa de vida do RS. Foram revisados artigos publicados de 1990 até 2010, e também suas referências. A inclusão dos artigos na presente revisão foi realizada de acordo com o que os autores julgaram relevante e não repetitivo, norteada pelos seguintes critérios: estudos realizados no Rio Grande do Sul, estudos de revisão publicados em revistas de maior impacto relacionados aos aspectos étnicos e genéticos e ao envelhecimento, estudos populacionais e não de amostras de conveniência.

\section{ENVELHECIMENTO DEMOGRÁFICO}

Em muitos países desenvolvidos, a proporção de indivíduos com idade igual ou acima de 65 anos é elevada e o número absoluto de idosos está em franca ascensão em todo mundo. Por exemplo, no ano de 1900 , apenas $4 \%$ da população dos Estados Unidos tinham idade igual ou acima de 65 anos; no final do século passado, a proporção era de $13 \%$ e estima-se que atinja $20 \%$ no ano de 2030. Apesar da crescente proporção de pessoas com 65 anos de idade ou mais nos EUA, o percentual nesse país ainda é menor em relação a países europeus, como Itália, onde $14,6 \%$ de sua população é composta por idosos, enquanto que os números de adultos idosos na Índia e na China excedem os de países desenvolvidos, como Estados Unidos. $^{3}$
No Japão, a expectativa média de vida ao nascer é de 82,7 anos, ocupando a primeira posição no ranking mundial da Organização das Nações Unidas (ONU). A China (Hong Kong) ocupa a segunda posição nesse ranking (82,2 anos). $\mathrm{Na}$ sequência, estão Islândia e Suíça ( 81,8 anos), Austrália (81,5 anos) e França (81,2 anos). O Brasil, segundo dados da ONU, ocupa a 92a - posição mundial, com uma expectativa de vida de 72,3 anos. ${ }^{4}$ Entre os idosos, o grupo daqueles com 80 85 anos ou mais deverá ser o segmento que apresentará o mais rápido crescimento. ${ }^{2}$

Nos países em desenvolvimento, em especial o Brasil, nos próximos 50 anos, a população deverá aumentar para 208,5 milhões, apresentando, no período de 2000 a 2050, uma taxa média de crescimento geométrico em torno de $0,4 \%$ ao ano, muito distante, portanto, da média dos cinquenta anos anteriores, o qual chegou a atingir 3,4\% ao ano entre 1960 e 1970.5,6 O Brasil, devido a seu vasto território (área de 8,5 milhões de $\mathrm{km}^{2}$, comportando 26 estados e 5.508 municípios) e suas enormes diversidades geográficas e socioeconômicas, étnicas e culturais, tornou os processos de transição demográfica (modificação relacionada a estrutura etária e sexo) e perfil epidemiológico regionalmente diferenciados ao longo desse período.

À medida que ocorre o desenvolvimento socioeconômico, científico e tecnológico de uma sociedade, melhorando as condições de vida, controle da fecundidade e natalidade, trabalho e saúde, ocorre gradualmente um aumento da longevidade (Figura 1) e uma substituição no padrão de morbi-mortalidade. Neste caso, o RS apresenta atualmente uma das maiores expectativas de vida do Brasil, bem como alta morbimortalidade por DCNT. 


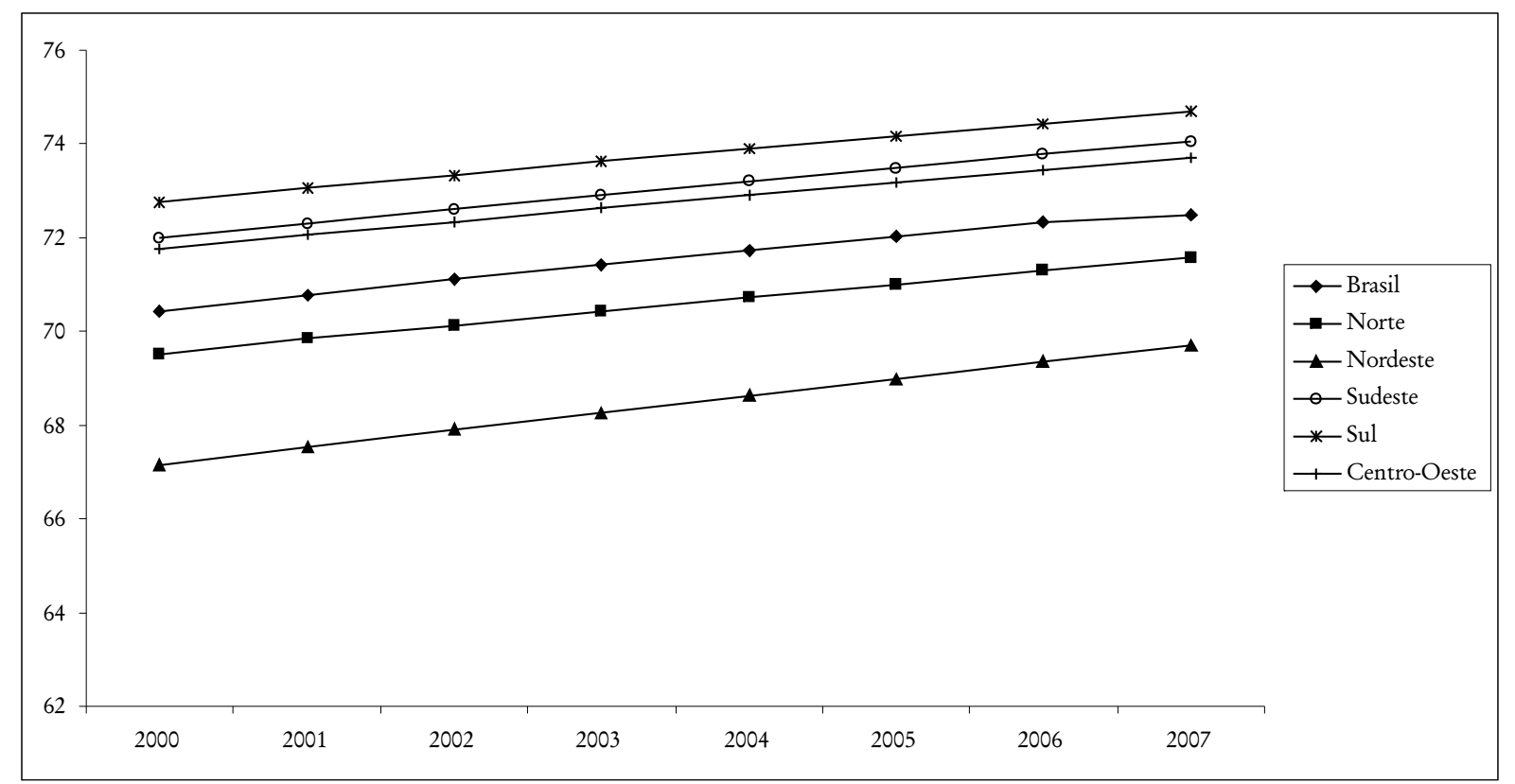

Figura 1 - Expectativa de vida ao nascer no Brasil, ambos os sexos, no período de 2000-2007. Fonte: IBGE/Projeções demográficas preliminares e DATASUS.

HISTÓRIA DA OCUPAÇ̃̃O E FORMAÇ̃̃O DA POPULAÇÃO GAÚCHA

O estado do RS está localizado na região geográfica mais meridional do Brasil; faz fronteira com Uruguai e Argentina e ocupa aproximadamente $3 \%$ do território brasileiro. Todo o seu território está abaixo do Trópico de Capricórnio. Em termos socioeconômicos, apresenta um dos maiores produtos internos brutos (PIB) e um destacado índice de desenvolvimento humano (IDH), avaliado através de indicadores de educação, renda e longevidade (quadro 1). ${ }^{7} \mathrm{Em}$ termos históricos e políticos, o RS foi um dos últimos estados a fazer parte do Brasil. No caso, o Tratado de Madri, acordado entre Espanha e Portugal em 1750, cumpriu importante papel para a definição das fronteiras do Estado. 
Quadro 1 - Características Gerais do Estado do Rio Grande do Sul - 2009.

\begin{tabular}{|l|l|}
\hline N. ${ }^{\circ}$ Municípios & 496 \\
\hline Capital & Porto Alegre \\
\hline Área & 282 mil km² \\
\hline Fuso Horário & -3 horas \\
\hline Clima & Subtropical ou temperado \\
\hline Vegetação & Campos e florestas \\
\hline Hidrografia & $\begin{array}{l}\text { Bacia do Uruguai e Rios que deságuam no } \\
\text { Atlântico }\end{array}$ \\
\hline Municípios mais populosos & $\begin{array}{l}\text { Porto Alegre, Caxias do Sul, Pelotas, } \\
\text { Canoas, Santa Maria, Novo Hamburgo, }\end{array}$ \\
& $\begin{array}{l}\text { Gravatá́, Viamão, São Leopoldo e Rio } \\
\text { Grande }\end{array}$ \\
\hline População estimada (n ${ }^{\circ}$ habitantes) & 10.845 .002 (6\% da população do Brasil) \\
\hline População Idosa & 1.125 .863 \\
\hline Taxa de crescimento populacional (\%) & 1,21 \\
\hline Alfabetização (\%) & 94,8 \\
\hline Total do PIB (\% em bilhões de Reais) & 3,8 \\
\hline Taxa bruta de natalidade & 12,9 \\
\hline $\begin{array}{l}\text { Número de óbitos infantis (menores de 1 ano) por 1.000 } \\
\text { nascidos vivos }\end{array}$ & 1,85 \\
\hline Esperança de vida ao nascer (anos) & 74,5 \\
\hline Esperança de vida aos 60 anos de idade (anos) & 21,32 \\
\hline Proporção de idosos (\%) & 12,3 \\
\hline Índice de envelhecimento & 27,61 \\
\hline Índice de Desenvolvimento Humano (IDH) & 0,869 \\
\hline
\end{tabular}

Taxa de crescimento populacional $=\%$ incremento médio anual; Taxa bruta de natalidade $=$ número de nascidos vivos $/ 1000$ habitantes/ano; Índice de envelhecimento $=$ número de idosos/100 indivíduos jovens/ano. Fonte: IBGE, FEE.

O Estado do RS apresenta uma enorme heterogeneidade cultural e étnica da sua sociedade, devido principalmente a colonização por açorianos, alemães e italianos, e sua miscigenação com povos autóctones locais e uma pequena parcela de indivíduos afrodescendentes. Inicialmente ocorreu a colonização espanhola e portuguesa, partilhando território com populações indígenas (guaranis, kaingang e xokleng) que aqui já viviam e, posteriormente, da imigração de diferentes etnias (polonesa, russa, árabe). ${ }^{8,9}$

Antes da vinda dos casais imigrantes, açorianos avulsos chegavam ao território riograndense, como em 1748 em Laguna, 1749 em Rio Grande, 1752 no Porto de Viamão, depois denominado Porto dos Casais. ${ }^{10} \mathrm{Em} 1780$, a partir do desenvolvimento das charqueadas, com ocupação da área de Pelotas, o tráfico negreiro começa a crescer. Contudo, é importante destacar que com a vinda de Dom João VI (1808) ao Brasil, começou o processo de colonização e "importação de mão de obra negra escrava”. ${ }^{11}$ Os negros foram trazidos como mão de obra escrava para trabalharem nas fazendas ou na linha de frente das grandes batalhas que aqui ocorriam no século XIX, como a Revolução Farroupilha, em 1835. 
Uma vez que uma das principais reivindicações da Revolução Farroupilha era o fim escravidão, após dez anos de luta e renegociação dos termos de rendição, o RS teve que aceitar a política escravagista que ainda permeava no Estado brasileiro. Este processo determinou a ocorrência de um número altíssimo de cartas de alforria, migração de comunidades negras para outros países, em especial para o Uruguai, e também a formação de quilombos cujos remanescentes existem ainda hoje. ${ }^{12}$ As chamadas comunidades quilombolas ainda conseguem manter hábitos de vida muito semelhantes aos dos seus antepassados.

Outras etnias, como os japoneses, também compuseram esse cenário de imigração. A imigração japonesa começou de fato a partir de 1950, com a chegada de 23 japoneses, que tinham $\mathrm{o}$ intuito de desenvolver a agricultura em solo gaúcho. $^{13}$

Todas essas etnias encontraram campo fértil para se instalarem, retomarem suas vidas e ajudar a construir o Estado do RS. A grande maior parte manteve seus costumes e cultura representados na culinária, na estrutura familiar, nas artes, no cultivo da terra, divisão do trabalho etc. A preservação da cultura de uma etnia é fundamental para não se perder a identidade e o sentido de unidade, que reforça a crença na origem comum. Atualmente, segundo a Síntese dos Indicadores Sociais de 2008, a população gaúcha é composta de $82,3 \%$ de brancos, $11,4 \%$ de pardos, $5,9 \%$ de negros e de $0,4 \%$ de amarelos ou indígenas. ${ }^{14}$

Estudos genéticos populacionais como o realizado por Marrero et al., ${ }^{15}$ utilizando DNA mitocondrial como marcador evolutivo, sugerem que em indivíduos aparentemente caucasianos existam $36 \%$ de contribuição genética ameríndia e até $16 \%$ de contribuição genética africana. Entretanto, além da estrutura multifacetada da sociedade gaúcha, característica da pluralidade cultural e étnica (genoma), que outros fatores podem estar contribuindo para um aumento da longevidade no RS? Este questionamento só pode ser percebido a partir de uma revisão interdisciplinar e que resgata aspectos históricos da formação populacional gaúcha.
Logo após a Primeira Guerra Mundial, criaram-se condições para que o $\mathrm{RS}$ recebesse um novo fluxo imigratório de poloneses, russos e japoneses. A grande diversidade étnica e cultural oriunda das diferentes regiões do mundo deu início ao processo de miscigenação entre tais populações, construindo, assim, o povo gaúcho com suas várias faces.

Paralelamente à formação da população gaúcha, o RS, assim como outras regiões mais desenvolvidas do Brasil, ao longo do século XX criou condições de controle nas suas taxas de mortalidade infantil e fecundidade. Este controle foi o pilar para o estabelecimento das condições de transição demográfica e do processo de envelhecimento populacional que no RS está em processo adiantado se comparado às regiões Norte e Nordeste. ${ }^{15}$

Tal fato, aliado a questões sanitárias, melhores condições de saúde, científica e tecnológica pode ter contribuído para uma maior longevidade no Estado e, consequentemente, para o processo de envelhecimento da população gaúcha. Essa alteração na estrutura etária da população gaúcha (aumento acelerado de indivíduos com mais de 60 anos) trouxe consigo não somente diversas alterações, tanto no padrão de morbi-mortalidade quanto na própria estrutura socioeconômica e cultural, mas também está proporcionando uma mudança de estilo de vida à medida que as pessoas se tornam mais velhas.

\section{EVOLUÇÃO DEMOGRÁFICA DO ENVELHECIMENTO POPULACIONAL GAÚCHO}

No Brasil, o processo de transição demográfica se iniciou a partir da década de 40 nos estados mais desenvolvidos do Brasil, incluindo o RS. ${ }^{16}$ $\mathrm{Um}$ aspecto importante que posteriormente contribuiu imensamente para a melhoria das condições de longevidade brasileira, também atingindo o estado gaúcho, foi o movimento da Reforma Sanitária brasileira, que ampliou o conceito de saúde. ${ }^{17}$ Nesse sentido, a saúde passou a ser entendida não somente como ausência de doença, mas sobretudo como um processo 
resultante das condições de alimentação, habitação, educação, renda, meio ambiente, trabalho, transporte, emprego, lazer, liberdade, acesso a terra e aos serviços de saúde. ${ }^{18}$

A população idosa do RS tem aumentado de modo significativo. Historicamente, no estado a expectativa de vida passou de 52,74 anos em 1903 para 66,7 anos em 1972, para 68,8 em 1980 e, de acordo com a Síntese dos Indicadores Sociais do IBGE, para 75 anos em 2007. ${ }^{19}$

Somente nos últimos dez anos, a proporção de pessoas acima de 60 anos no estado cresceu $47 \%$, enquanto o da população total, apenas $15 \%$. O contingente de idosos está vivendo em média 75 anos, totalizando 1,4 milhão de pessoas. Desta população, $56 \%$ têm entre 60 e 69 anos, $16 \%$ vivem sozinhos, $20 \%$ são analfabetos e $89 \%$ vivem de pensão. ${ }^{18}$

Em relação ao gênero, a expectativa de vida passou de 63,6 anos nos homens em 1972, para
65,1 em 1980, para 71,4 em 2007. ${ }^{19}$ Entre as mulheres, a expectativa de vida passou de 70 anos para 72,9 e, depois, para 78,8. E, dentre os municípios do RS com as maiores expectativas de vida, Carlos Barbosa foi o que apresentou a maior (quadro 2). ${ }^{19-21}$ No Brasil, bem como no RS, as mulheres têm maior esperança de vida ao nascer, diferença que está ao redor de oito anos. Como resultado, o número de mulheres idosas é superior ao número de homens, sobretudo nas faixas de idade mais avançadas. ${ }^{14}$

O aumento da expectativa de vida e, consequentemente, da longevidade da população gaúcha, se deve em grande parte ao controle das doenças infecciosas na infância, à queda da mortalidade infantil, devido a melhorias médicosanitárias, e aos avanços científicos que promovem a descoberta de novas tecnologias e medicamentos que combatem a incidência, prevalência e mortalidade por DCTN, como ocorre em todo o país, de forma geral. ${ }^{19}$

Quadro 2 - Composição Étnica dos Municípios do Rio Grande do Sul com maior expectativa de vida - média entre os períodos de 2001 a 2003.

\begin{tabular}{|l|c|c|c|c|}
\hline \multicolumn{1}{|c|}{ Município } & $\begin{array}{c}\text { Composição } \\
\text { étnica principal }\end{array}$ & $\begin{array}{c}\text { Expectativa de } \\
\text { vida mulheres }\end{array}$ & $\begin{array}{c}\text { Expectativa de } \\
\text { vida homens }\end{array}$ & $\begin{array}{c}\text { Expectativa de } \\
\text { vida total }\end{array}$ \\
\hline Carlos Barbosa & Italiana & 80,7 & 74,7 & 77,7 \\
\hline Nova Prata & Italiana & 82,4 & 72,6 & 77,3 \\
\hline Sarandi & Brasileira & 79,8 & 74,2 & 77,1 \\
\hline Flores da Cunha & Italiana & 81,7 & 72,7 & 76,9 \\
\hline Garibaldi & Italiana & 80,2 & 73,0 & 76,6 \\
\hline Encantado & Açoriana & 79,7 & 72,9 & 76,5 \\
\hline Rolante & Portuguesa & 81,1 & 72,6 & 76,5 \\
\hline Bento Gonçalves & Italiana & 81,1 & 72,0 & 76,4 \\
\hline $\begin{array}{l}\text { Santo Antônio da } \\
\text { Patrulha }\end{array}$ & Portuguesa & 84,2 & 70,5 & 76,4 \\
\hline Guaporé & Italiana & 80,5 & 71,9 & 76,2 \\
\hline
\end{tabular}

Fonte: SES/DAS; IBGE. Obs.: Dados para os municípios com mais de 17,000 habitantes. 
PERFIL EPIDEMIOLÓGICO DOS IDOSOS DO RIO GRANDE DO SUL E PREVENÇÃO DE DOENÇAS CRÔNICAS NÃO-TRANSMISSIVEIS

Com relação ao perfil de morbi-mortalidade dos idosos do RS, as doenças do sistema circulatório, neoplasias e respiratórias são as mais prevalentes (quadro 3). ${ }^{22}$ Dados referentes ao ano de 2007 mostraram que houve pequena inversão na porcentagem de mortalidade entre os sexos, ou seja, nesse ano-base, a porcentagem de mortalidade geral no RS foi maior nas mulheres (quadro 4). Destes óbitos, 25.226 eram idosos do sexo masculino e 25.518 eram do sexo feminino.

Quadro 3 - Morbidades hospitalares de idosos atendidos pelo Sistema Único de Saúde (SUS) segundo classificação internacional das doenças (CID-10), LOCAL, no ano de 2007.

\begin{tabular}{|l|c|c|}
\hline \multicolumn{1}{|c|}{ Capítulo CID-BR-10 } & Internações (n) & $\%$ \\
\hline IX. Doenças do aparelho circulatório & 4.816 & 28,05 \\
\hline X. Doenças do aparelho respiratório & 3.562 & 20,74 \\
\hline II. Neoplasias (tumores) & 1.831 & 10,66 \\
\hline XI. Doenças do aparelho digestivo & 1.692 & 9,85 \\
\hline XIV. Doenças do aparelho geniturinário & 993 & 5,78 \\
\hline Outras doenças e causas externas & 4275 & 24,84 \\
\hline TOTAL & 17.169 & 100 \\
\hline
\end{tabular}

Fonte: Ministério da Saúde - Sistema de Informações Hospitalares do SUS (SIH/SUS).

Quadro 4 - Óbitos em idosos por residência segundo sexo pela classificação internacional das doenças (CID-10), no ano de 2007.

\begin{tabular}{|l|c|c|c|}
\hline \multicolumn{1}{|c|}{ Capítulo CID-10 } & $\begin{array}{c}\text { Masculino } \\
(\mathrm{n})\end{array}$ & $\begin{array}{c}\text { Feminino } \\
(\mathrm{n})\end{array}$ & $\begin{array}{c}\text { Total } \\
(\mathrm{n})\end{array}$ \\
\hline IX. Doenças do aparelho circulatório & 8,651 & 10,307 & 18,958 \\
\hline II. Neoplasias (tumores) & 6,108 & 4,589 & 10,697 \\
\hline X. Doenças do aparelho respiratório & 4,122 & 3,367 & 7,489 \\
\hline IV. Doenças endócrinas nutricionais e metabólicas & 1,272 & 1,866 & 3,138 \\
\hline XVIII. Sintomas sinais e achados anormais, exames clínicos e laboratoriais & 1,191 & 1,334 & 2,525 \\
\hline XI. Doenças do aparelho digestivo & 1,119 & 1,056 & 2,175 \\
\hline VI. Doenças do sistema nervoso & 590 & 923 & 1,513 \\
\hline XX. Causas externas de morbidade e mortalidade & 838 & 525 & 1,363 \\
\hline I. Algumas doenças infecciosas e parasitárias & 497 & 529 & 1,026 \\
\hline XIV. Doenças do aparelho geniturinário & 465 & 532 & 997 \\
\hline V. Transtornos mentais e comportame ntais & 203 & 133 & 336 \\
\hline III. Doenças sangue órgãos hematológicos e transtornos imunitários & 88 & 117 & 205 \\
\hline XIII. Doenças sistema osteomuscular e tecido conjuntivo & 44 & 140 & 184 \\
\hline XII. Doenças da pele e do tecido subcutâneo & 31 & 76 & 107 \\
\hline XVII. Malformações congênitas, defo rmidades e anomalias cromossômicas & 7 & 23 & 30 \\
\hline VIII. Doenças do ouvido e da apófise mastóide & - & 1 & 1 \\
\hline TOTAL & 25,226 & 25,518 & 50,744 \\
\hline
\end{tabular}

Fonte: Ministério da Saúde - Sistema de Informações Hospitalares do SUS (SIH/SUS). 
As doenças cardiovasculares e as neoplasias são as primeiras causas de morte em indivíduos com idade acima de 60 anos, e estão diretamente relacionadas ao envelhecimento. Dentre as neoplasias, a de mama é a primeira causa de câncer nas mulheres, enquanto que a de próstata se encontra entre as mais frequentes no sexo masculino, na maioria dos grandes centros urbanos do país, incluindo o RS..$^{19,20}$

Com base nos dados levantados da fonte de dados do DATASUS, o Brasil já demonstra grande preocupação com o deslocamento da prevalência das doenças infecciosas para as doenças crônicas não-transmissíveis (DCNT), pois os dados mostram que as DCNT são responsáveis por aproximadamente $60 \%$ das mortes e incapacidades mundiais e as projeções indicam que em 2020 essa porcentagem possa alcançar os $73 \%$. Segundo a OMS e a Organização Panamericana de Saúde (OPAS), em 2001 as DCNT foram responsáveis por $62 \%$ de todas as mortes e $39 \%$ de todas as internações hospitalares aqui no Brasil. ${ }^{21,22}$

Alguns estudos conduzidos aqui no Brasil têm demonstrado que o estilo de vida, principalmente o sedentarismo e a dieta, são fatores ambientais fortemente associados com o aumento $\mathrm{da}$ prevalência de DCNT e mortalidade. Enfatizase a necessidade de mudanças no estilo de vida que promovam a prática regular de atividade física aliada a uma dieta balanceada, ainda na infância. ${ }^{23-25}$

$\mathrm{Na}$ década de 1990 alguns autores demonstraram que a atividade física regular pode reduzir o risco de DCNT em idosos, destacando doença coronária, a hipertensão, diabetes mellitus 2 (DM2), distúrbios metabólicos (obesidade) bem como de distúrbios do humor e depressão. ${ }^{26}$ Alguns estudos realizados no Brasil mostraram que idosos sedentários são mais acometidos por DCNT, sobretudo as osteomusculares, doenças vasculares e cardíacas, hipertensão arterial e diabetes mellitus e as mulheres apresentam maior prevalência destas doenças em relação aos homens. ${ }^{27}$

Em estudo transversal realizado em sete estados brasileiros, incluindo as regiões Sul e
Nordeste ( $n=4.060$ adultos e $n=4.003$ idosos), verificou-se que a prevalência de sedentarismo foi de 31,8\% (IC95\%: 30,4-33,2) e 58\% (IC95\%: $56,4-59,5)$ para adultos e idosos, respectivamente, sendo que a Região Nordeste apresentou maior prevalência de sedentarismo em homens que na região Sul. Entretanto, a Região Sul apresentou alta prevalência de sedentarismo $(47,3 \%$ na amostra de idosos [média de idade 73,9 anos $\pm 7,0$ ] e $24 \%$ na amostra de adultos [a média de idade 45,5 anos $\pm 9,6])$. O sedentarismo foi significativamente mais frequente entre os homens em comparação às mulheres, sendo as diferenças marcantes entre os adultos e de pequena magnitude entre os idosos. Para ambos os grupos (idosos e adultos), o sedentarismo tendeu a crescer com o aumento da idade. Embora estatisticamente significativas, as diferenças relacionadas à cor da pele entre os idosos foram de magnitude pequena. Além disso, aproximadamente dois terços dos idosos classificaram sua saúde como regular ou ruim, ao passo que, entre os adultos, esse percentual foi próximo de $50 \%$. O percentual de indivíduos que classificou a atividade física como um dos três comportamentos mais importantes para a manutenção da saúde foi de $61 \%$ entre os adultos e $74 \%$ entre os idosos. ${ }^{28}$

Aliado a esse fator, outros estudos também têm avaliado o papel da dieta na promoção e prevenção de DCNT em idosos. Por exemplo, um estudo de revisão e descrição das principais ações na implantação do sistema nacional de vigilância e prevenção de DCNT realizado pelo Ministério da Saúde mostrou que em todas as regiões do Brasil se observou consumo de frutas, legumes e verduras sempre inferior entre pessoas de menor escolaridade, ainda que se apresentasse baixo, de maneira geral, para todos os níveis de escolaridade. $\mathrm{O}$ consumo de frutas, legumes e verduras recomendado pela OMS, de cinco porções ao dia (equivalente a 400 gramas/dia), foi identificado em menos de $3 \%$ da população das capitais pesquisadas; cerca de $50 \%$ dessa população ingere apenas uma a três porções ao dia. As capitais com menor consumo de frutas, legumes e verduras foram as da Região Norte (Manaus e Belém). Os alimentos de origem animal ricos em 
gorduras (gordura visível da carne; frango com pele; leite integral) são mais consumidos pela população de menor escolaridade. ${ }^{29}$

Braga e Lautert ${ }^{30}$ avaliaram 220 idosos da cidade de Porto Alegre (Região Sul), para conhecer as condições de vida e o perfil sociodemográfico. Os resultados do estudo mostraram que $92,27 \%$ dos idosos consumiam vegetais e verduras com frequência, acompanhados de grãos, frutas, leite e derivados e carne branca. A grande maioria dos idosos entrevistados $(95,46 \%)$ relatou ingerir três ou mais refeições ao dia e consumir verduras e grãos. Em relação ao hábito de fumar, 184 $(83,64 \%)$ idosos referiram não fumar e apenas 36 (16,36\%) possuem esse hábito; destes, $12(5,45 \%)$ fumam mais de 16 cigarros por dia, 16 (7,27\%) de cinco a 15 cigarros por dia e oito $(3,64 \%)$ fumam até cinco cigarros por dia.

O estudo de Braga \& Lautert ${ }^{30}$ demonstrou que idosos investigados da cidade de Porto Alegre têm preocupação com a qualidade dos alimentos ingeridos, tanto no que se refere ao tipo de dieta, bem como a frequência em que são ingeridos. Além disso, demonstrou que esses idosos compreendem que uma dieta equilibrada e adequada tem importante papel na saúde de um indivíduo e pode ajudar no controle e prevenção de doenças, bem como refletir em melhor qualidade de vida.

No entanto, mesmo que alguns estudos mostrem que idosos de determinada região geográfica tenham uma dieta saudável, percebese que a dieta da população brasileira, independentemente da faixa etária, é rica em gorduras saturadas e pobre em alimentos ricos em fibras. Esse panorama nutricional, aliado ao sedentarismo e ao perfil genético, é um dos principais fatores etiológicos das DCNT, como a obesidade, DM2 e a hipertensão. ${ }^{31}$

\section{PERFIL GENÉTICO ASSOCIADO A DOENCAS CRÔNICAS NÃO-TRANSMISSÍVEIS E ETNIA}

Muito pouco se sabe sobre o perfil genético para as diversas DCNT, bem como o padrão de herança de genes de acordo com a origem étnica dos idosos do RS. Contudo, no caso da doença de Alzeimer (DA), existe um volume maior de evidências em diferentes populações no mundo. Por exemplo, estudos mostram que caucasianos apresentam alta incidência e prevalência de DA, bem como grupos não-caucasianos, como latinos não-brancos e afroamericanos. ${ }^{32}$ Além disso, está bem estabelecido na literatura que fatores de risco para o desenvolvimento da DA em populações brancas incluem idade, história familiar, sexo feminino e a presença de uma ou duas cópias do alelo E4 do gene da apolipoproteína E. ${ }^{33}$ Estudos mostraram que parentes de pacientes brancos com DA estão em maior risco de desenvolver a doença do que indivíduos sem parentesco para o desenvolvimento de demência, e que esses riscos são maiores com o aumento da idade, no sexo feminino, e com probabilidade de levar uma ou duas cópias do alelo APOE 4 (E4E4). ${ }^{33-36}$

Uma meta-análise conduzida por Farrer et al. ${ }^{33}$ com diferentes etnias encontrou uma razão de chance (OR) para o desenvolvimento de DA em portadores do genótipo E4/E4 de 14,9 e 33,1 nas populações caucasianas e japonesas, respectivamente. Bertram et al. ${ }^{37}$ obtiveram OR para o genótipo E3/E4 versus E3/E3 de 2,8 e 3,9 (populações caucasianas e asiáticas, respectivamente). Nas mesmas populações, a presença do genótipo E4/E4 leva a riscos de desenvolvimento de DA de 11,8 e 21,8 maiores, quando comparados com o genótipo E3/E3 (populações caucasianas e asiáticas, respectivamente). Esses dados demonstram a aditividade de risco para cada alelo $\mathrm{E} 4$, além de demonstrarem a modulação do risco de acordo com o grupo étnico.

Em relação ao polimorfismo da APOE, já existem diversos estudos mostrando as frequências alélicas em diferentes etnias. Os estudos mostram que em populações de origem europeia (predominantemente caucasianos, como é o caso da população dos municípios gaúchos de Gravataí e Veranópolis), a frequência dos alelos E2, E3 e E4 são $0,05-0,10, \quad 0,7-0,8, \quad 0,10-0,15$, respectivamente..$^{38}$ Ainda que o aleloE3 seja o mais 
comum (selvagem), enquanto E4 é mais frequente em algumas populações da África, o Norte da Europa, Oceania e nativos americanos, a frequência alélica da APOE é variável nas populações (o locus da APOE é polimórfico de $16-53 \%$ conforme a população). ${ }^{39-43}$ Por exemplo: as populações do Brasil e dos Estados Unidos (ambas as populações são multiétnicas) são caracterizadas pela baixa frequência do alelo $\mathrm{E} 2 .^{44,45}$ Nas populações em geral, o alelo E2 está associado com baixos níveis de colesterol plasmático total, LDL-c, ApoB e elevados níveis de triglicérides, comparados com o alelo E3. Por outro lado, o alelo E4 está associado com altos níveis de colesterol total, LDL-c e Apo B. ${ }^{46}$

O fator etnorracial desempenha papel-chave na modulação do risco para as DCNT, tendo em vista a herança de alelos e de hábitos de vida que podem aumentar a predisposição a determinadas DCNT. Por isso, a importância de realizar estudos em diferentes populações, onde as DCNT são muito prevalentes no segmento idoso.

Por outro lado, estudos de associação isolados entre marcadores genéticos e DCNT em idosos também têm sido conduzidos com frequência no RS. Por exemplo, alguns estudos envolvendo marcadores genéticos foram conduzidos com idosos com diferentes DCNT residentes no município de Gravataí e de Veranópolis. Gravataí, é um município da região metropolitana de Porto Alegre que apresenta aspectos étnicos, demográficos e sanitários "sintetizadores da população gaúcha”. Isto porque sua origem étnica e cultural é mesclada pelas grandes levas migratórias ocorridas no estado, ao longo do século XIX e XX, sobretudo por açorianos, alemães e italianos. No caso, havendo miscigenação acentuada, principalmente com indivíduos originários dos principais grupos indígenas (guaranis) que povoavam o estado. Já Veranópolis é um município da Serra Gaúcha, com uma origem étnica composta por italianos e, secundariamente, poloneses, sendo que os habitantes mais antigos dessa região foram os indígenas e os portugueses.
Com relação à predisposição genética, Gottlieb et al. ${ }^{47}$ conduziram um estudo caso-controle (100 idosos com síndrome metabólica (SM), sem DCV e 368 idosos saudáveis) do município de Gravataí, para verificar a associação entre o polimorfismo do gene do receptor da Leptina e SM em idosos. Observaram diferenças nas frequências alélicas e genotípicas entre os grupos $\left(\chi^{2}=14,862\right.$; $p=0,005)$. O estudo mostrou uma redução do genótipo $G l n / G l n$ e um aumento do genótipo $\mathrm{Arg} / \mathrm{Arg}$ em indivíduos com SM. Também foi observado risco de 2.548 (IC 95\% = 1,466-4,429) dos idosos com SM serem portadores do alelo Arg em relação aos idosos saudáveis. Além disso, idosos obesos também apresentaram uma alta frequência do genótipo $\mathrm{Arg} / \mathrm{Arg}$, quando comparados com os idosos saudáveis $\left(\chi^{2}=6,634\right.$; $p=0,036)$. Os resultados desse estudo sugerem que o polimorfismo do gene do receptor da Leptina, principalmente a variante $A r g$, pode aumentar a predisposição para o desencadeamento de obesidade e SM, que são consideradas DCNT com alta prevalência em idosos.

Outro estudo, conduzido pelo mesmo grupo de pesquisa, investigou a associação dos níveis de lipoproteína de baixa densidade oxidada (OxLDL) com fatores de risco cardiovasculares clássicos e com os polimorfismos genéticos da enzima superóxido dismutase dependente de manganês (SOD2) e apolipoproteína E (APO E) em idosos também do município de Gravataí. Os resultados mostraram associação positiva entre níveis de OxLDL com pressão arterial sistólica (PAS), pressão arterial diastólica (PAD), circunferência abdominal e porcentagem de gordura corporal. Idosos com o genótipo VV do polimorfismo da SOD2 apresentaram níveis mais elevados de OxLDL, principalmente em indivíduos afetados por DM2. Esta associação foi independente de outros fatores de risco cardiovasculares clássicos e do polimorfismo da APOE, que está, por sua vez, relacionado a maiores níveis de LDL-c e DCNT como as cardiovasculares e as neurodegenrativas (demência do tipo Alzheimer).$^{48}$ Entretanto, em ambos os estudos a amostra foi composta predominantemente por idosos de origem caucasiana, o que 
impediu análises mais complexas e acuradas para se avaliar a associação entre os genótipos da leptina, SOD2 e APOE e etnia.

Schwanke et al. ${ }^{49}$ realizaram estudo de associação entre o polimorfismo do gene da APOE e fatores de risco cardiovasculares em idosos longevos do município de Veranópolis-RS. Nesse estudo, os autores ${ }^{49}$ encontraram as seguintes frequências dos alelos E2, E3 e E4 da APOE: 0,05, 0,84 e 0,11, respectivamente; e para os genótipos: $\mathrm{E} 3 \mathrm{E} 3(0,70), \mathrm{E} 3 \mathrm{E} 4(0,22), \mathrm{E} 2 \mathrm{E} 3$ $(0,06)$, e E2E2 $(0,02)$. Vinte e dois por cento da amostra possuíam pelo menos um alelo $\mathrm{E} 4$, o que aumenta a suscetibilidade dos indivíduos a maiores níveis de LDL-c do que indivíduos não portadores deste alelo. Isso se confirmou quando se observou que idosos com o genótipo E3E4 apresentaram níveis significativamente mais elevados de LDL-colesterol e de fibrinogênio do que os indivíduos com o genótipo E3E3. Por outro lado, os idosos com o genótipo E3E3 apresentaram níveis mais elevados de ácido úrico, pressão arterial diastólica e Índice de Massa Corporal (IMC). Surpreendentemente, a média da idade dos idosos portadores do genótipo E3E4 foi significativamente maior do que a dos portadores do genótipo E3E3 $(85,36 \pm 3,23$ anos $\mathrm{x} 82,72 \pm 3,1$ anos, respectivamente).

Esses dados sugerem que pode estar ocorrendo um balanço entre fatores protetores ou neutros e os fatores de risco cardiovasculares entre os portadores dos diferentes genótipos, atenuando os efeitos negativos do alelo E4, ou que existem outras interações genéticas e ambientais (dieta e atividade física, por exemplo) adicionais agindo no sentido de anular ou diminuir os efeitos negativos do alelo $\mathrm{E} 4$ ou de diminuir os efeitos benéficos do genótipo E3E3. ${ }^{49} \mathrm{Nesse}$ caso, como a amostra foi composta por idosos caucasianos, a frequência alélica e genotípica foi muito semelhante à das frequências de outros estudos como citado anteriormente.

Aliado ao componente étnico e aos polimorfismos genéticos associados, é importante comentar alguns hábitos alimentares e de estilo de vida peculiares dos idosos tanto do município de Gravataí, quanto de Veranópolis, que devem ser levados em conta como possíveis fatores protetores contra os efeitos adversos de um perfil genético "desfavorável", como por exemplo, ser portador do alelo Arg da Leptina, V da SOD2 e E4 da APOE. O alelo $A r g$ está associado a uma maior predisposição a obesidade e $\mathrm{SM}$; o alelo $\mathrm{V}$ da SOD2 já associado com concentração mais elevada de ânion superóxido (radical livre); e o alelo E4 da APOE está associado com níveis elevados de colesterol total, LDL-c e Apo B.

Um estudo conduzido por Siviero et al.$^{50} \mathrm{com}$ idosos socialmente ativos (participantes de grupos de terceira idade) do município de Gravataí mostrou que os mesmos ingeriam menos calorias do que o recomendado nas Recommended Dietary Allowances (RDAs). Observou-se ainda maior consumo de proteínas do que de carboidratos, enquanto que o consumo de lipídeos ficou dentro dos padrões recomendados pela OMS. ${ }^{51}$ Além disso, foi detectado que $47 \%$ dos idosos de Gravataí consumiam uma maçã por dia, sendo que o cardápio diário incluía no mínimo três porções de frutas e duas de verduras, o que é recomendado pela OMS.

Com relação ao consumo de maçã, sabe-se que essa fruta é o terceiro alimento com maior concentração de flavonóides na dieta humana. E os estudos mostram que o flavonóide mais ativo da maçã é a quercitina, por seu efeito antioxidante. Além disso, a maçã também possui altas concentrações de boro, que dentre suas múltiplas propriedades está a de hipolemiante e também antioxidante. Coincidentemente, o município de Veranópolis é considerado o berço da produção de maçãs no estado, por possuir clima e solo favoráveis ao seu cultivo, e por muito tempo ocupou a primeira posição no ranking dos municípios mais longevos do Brasil. ${ }^{52,53}$

Além da maçã, outro hábito frequente dos idosos é o consumo de chimarrão (erva mate), que possui diversos componentes bioativos, destacando-se o cálcio, fósforo, ferro, magnésio, manganês, potássio, ácidos fólico e caféico, polifenóis, vitaminas: A, B1, B2, C e E, que desempenham funções essenciais no organismo, como proteção antioxidante. 
Siviero et al.$^{54}$ referiram uma ingestão de diária de frutas, hortaliças e vinho em $50 \%$ dos idosos entrevistados. Um hábito muito disseminado entre os idosos de Veranópolis é o consumo de chá de maçã e de vinho, que têm potencial antioxidante e anticarcinogênico. Em média, os idosos consumiam $284 \mathrm{~mL} /$ dia de vinho.

Outro estudo conduzido com idosos octagenários e nonagenários de Veranópolis para avaliar a prática de atividade física, envolvendo a rotina de trabalho, através do consumo energético $\mathrm{em} \mathrm{kcl} /$ semana. Foi demonstrado que tais idosos possuem um gasto energético similar aos adultos mais jovens que se encontram em idade produtiva. ${ }^{55}$

Por outro lado, é importante lembrar que um hábito alimentar muito comum entre os gaúchos, independentemente da idade e do município, é o consumo da carne vermelha assada, o chamado churrasco. Este, além de conter níveis elevados de gordura, contém aminas heterocíclicas, um produto da reação entre a creatina com os aminoácidos, assim como hidrocarbonetos aromáticos policíclicos, os compostos encontrados na comida queimada, ambos já tendo sido testados como capazes de promover câncer de mama. ${ }^{56}$ Entretanto, o consumo de frutas e verduras, ricas em fitoesteróis, vitamina C, E e betacarotenos, pode atuar como protetor contra o câncer de mama e outras DCNT, por seus efeitos antioxidantes no metabolismo do estrógeno e na redução da proliferação celular, entre outros mecanismos. ${ }^{57,58}$

Esse conjunto de informações demonstra que, apesar de parte dos idosos investigados apresentar polimorfismos genéticos predisponentes a desenvolver alguma DCNT, o hábito alimentar e a prática de atividade física que, no caso, envolveu a rotina de trabalho (idosos Veranópolis) ou participar de grupos de terceira idade (idosos de Gravataí participavam de diversas atividades, como por exemplo, a dança) - pode ter promovido mecanismos fisiológicos de proteção que contrabalançam os efeitos de um perfil genético "desfavorável" para determinado ambiente. Dessa forma, sugere-se que não apenas a exposição ao fator de risco, mas a combinação de perfis genéticos, etnia e a exposição, é que determina o risco de desencadeamento de DCNT.

Neste contexto, é imprescindível construir políticas de atenção à saúde, não somente ao idoso, mas a todas faixas etárias, que introduzam modelos de vigilância à saúde adequados à realidade da população, priorizando os aspectos biológicos, ambientais, como estilo de vida e o entorno socioeconômico e cultural, para a promoção de melhor qualidade de vida e envelhecimento saudável.

\section{CONSIDERAÇÕES FINAIS}

O Rio Grande do Sul apresenta um perfil étnico e cultural peculiar e heterogêneo. Além disso, os estudos mostram que a população brasileira apresenta extensiva mistura genômica e um forte imprint da onda de maciça imigração que ocorreu nos séculos XIX e XX.

Essa alta variabilidade gênica ancestral sugere que cada brasileiro tem uma singular proporção de ameríndios, europeus e africanos no seu mosaico genômico, o que pode ter implicações na epidemiologia e diagnóstico, não somente das doenças genéticas, mas também das DCNT. ${ }^{59}$

Essa diversidade, marcada principalmente pelas características genéticas de uma dada etnia, além de outros fatores (dieta e estilo de vida), pode estar influenciando a expectativa de vida e a longevidade da população do RS. Contudo, a resposta para diversas questões sobre o processo de envelhecimento, tais como quando e por que teremos cabelos brancos ou desenvolveremos DCNT, pode residir justamente na interação entre etnia, genoma e estilo de vida.

O RS já demonstra contornos de uma sociedade em acelerado processo de envelhecimento, representado pela queda da fecundidade/natalidade, aumento da expectativa de vida de sua população e alta prevalência de DCNT. ${ }^{19,21}$ Neste quesito, o RS ocupa o primeiro 
lugar no ranking de mortalidade por neoplasias de mama e de próstata, bem como no das doenças cardiovasculares. ${ }^{18,19}$

Dados da OMS apontam que somente o controle da hipertensão arterial sistêmica reduziria em 35 a 40\% a incidência de acidente vascular cerebral (AVC), 20 a 25\% de infarto agudo do miocárdio (IAM) e mais de $50 \%$ de insuficiência cardíaca congestiva. Neoplasias de mama, colo do útero e próstata poderiam ser prevenidas em $40 \%$ ou mais com a realização de exames diagnósticos periódicos. ${ }^{60}$

Considerando-se a realidade do RS, onde existem alta morbidade hospitalar e mortalidade por doenças cardiovasculares, doenças respiratórias e neoplasias, observa-se a grande necessidade de desenvolvimento e consolidação de estratégias de saúde pública que auxiliem na prevenção das DCNT, tanto em idosos quanto em grupos etários mais jovens, e que tenham como objetivo diminuir e controlar a morbidade e os custos nas próximas décadas. Essas estratégias devem contemplar um programa de alimentação

\section{REFERÊNCIAS}

1. Júnior CSD, Costa SC, Lacerda MA. O envelhecimento da população brasileira: uma análise de conteúdo das páginas da REBEP. Rev Bras Geriatr Gerontol 2006; 9(2). [ Acesso 10 jun 2006].Disponível em: <http://

www.unati.uerj.br/tse/

scielo.php?script $=$ sci_arttext\&pid $=\mathrm{S} 1809$ -

98232006000200002\&lng $=$ pt\&nrm $=$ iso $>$

2. Troen RB. The Biology of Aging. Mt Sinai J Med 2003; 70(1):3-22.

3. Fried PL. Epidemiology of Aging. Rev Epidemiology 2000; 22(1):95-106.

4. World Health Organization( WHO). World Health Statistics; progress on the health-related millennium development goals (MDGs). 2009.[Acesso em 09 março de 2010]. Disponível em: URL: http://www.who.int/whosis/ whostat/2009/en/index.html

5. Chaimowickz FA. Saúde dos idosos brasileiros às vésperas do século XXI: problemas, projeções, alternativas. Rev Saude Publica 1997; 31(2):184-200. saudável, equilibrada e adequada para a nossa população.

Ou seja, devemos criar as nossas próprias $\mathrm{RDAs}$, programas de incentivo a prática de atividade física regular, bem como de manutenção ou resgate de hábitos culturais de determinada etnia, que atendam às condições biológicas e capacidades, não somente para os idosos, mas ao longo de todo o desenvolvimento humano. É importante destacar que a interação entre o ambiente e variabilidade genética individual pode modificar a relação entre genes e o binômio saúde/doença, e pode explicar as diferenças na susceptibilidade a desenvolver DCNT em diferentes populações.

Por isso, é fundamental um olhar abrangente para a questão do envelhecimento não somente da população gaúcha, mas da população idosa de todo o Brasil, que é caracterizado também pela heterogeneidade étnica. Existem muitos fatores envolvidos no fenótipo do envelhecimento, além do estilo de vida, que potencialmente podem estar influenciando a longevidade e o desencadeamento de DCNT.

6. Moreira MM. Envelhecimento da população brasileira: intensidade, feminização e dependência. Rev Bras de Estudos Populacionais 1998; 15(1): 79-93.

7. Organização das Nações Unidas. Programa das Nações Unidas para o Desenvolvimento (PNUD) : ranking do IDH dos estados do Brasil em 2005.[Acesso em 10 out. 2005]. Disponível em: URL: http:// http:// www.pnud.org.br/idh/

8. Schimitz PI. Índios Guaranis, Kaingang e Xokleng: territórios indígenas e fronteiras. In: Moreira, Viel LF (Org.). Instituições, Fronteiras e Política na História SulAmericana. Curitiba: Juruá Editora; 2007. p.138-9.

9. Herédia V. A imigração européia no século passado: o programa de colonização no Rio Grande do Sul. Scripta Nova 2001; 94(10). [Acesso em 1 ago. 2001].Disponível em: URL: http://www.ub.es/geocrit/sn-9410.htm 
10. Fagundes EM. Bagé: no caminho da História do Rio Grande do Sul. Porto Alegre: Martins Livreiro-Editor; 1995.

11. Maestri M. O escravo no Rio Grande do Sul: trabalho, resistência, sociedade. 3.ed. Porto Alegre: EdiUFRGS; 2006.

12. Mello CFCB. Senhores da História: a construção do Brasil em dois manuais didáticos de história na segunda metade do século XIX. São Paulo Tese [Doutorado em História] Universidade de São Paulo; 1997.

13. Portal da Câmara Municipal de Porto Alegre. Companhia de processamento de dados do município de Porto Alegre. [Acesso em 11 de Março de 2010] Disponível em: URL: http:// lproweb.procempa.com.br/pmpa/prefpoa/ camarapoa/default.php?reg $=7373 \& \mathrm{p}_{-}$ secao $=56 \& \mathrm{di}=2008-10-03$

14. Instituto Brasileiro de Geografia e Estatística (IBGE). População total e respectiva distribuição percentual, por cor ou raça, segundo as grandes regiões, unidades da federação e Regiões Metropolitanas:. síntese dos inidicadores sociais 2008. São Paulo: IBGE; 2007. [Acesso em 12 out 2008]. Disponível em: URL: http://www.ibge.br.

15. Marrero AR, et al. Heterogeneity of the genome ancestry of individuals classified as white in the state of Rio Grande do Sul,. Am J Hum Biol 2005;17(1):496-506.

16. Nasri F. O envelhecimento populacional no Brasil. Einstein 2008;6(Supl 1):S4-6.

17. Brasil. Ministério da Saúde. VIII Conferência Nacional de Saúde. Brasília: Ministério da Saúde; 1986.

18. Instituto Brasileiro de Geografia e Estatística. Indicadores sociodemográficos e de saúde no Brasil. 2009. [Acesso em 10 de Nov. 2009]. Disponível em http://www.ibge.br

19. Secretaria Estadual de Saúde; Núcleo de Informações em Saúde-NIS. Sistema de informação sobre mortalidade no Rio Grande do Sul. [Acesso em 10 Nov. 2009]. Disponível em: URL: http://www.saude.rs.gov.br/wsa/portal/ index.jsp?menu = organograma \&cod =746

20. Departamento de Informática do SUS. Informação de saúde, epidemiológicas e morbidades. [Acesso em 20 Nov. 2009].Disponível em: URL: http:// www2.datasus.gov.br/DATASUS/ index.php?area $=0203$

21. Organização Mundial da Saúde (OMS). Instituto Nacional do Câncer Ministério da Saúde.Brasília : Ministério da Saúde; 2002. 12p.
22. Organização Panamericana de Saúde. Política de alimentação e nutrição Brasília : Ministério da Saúde; 2004. [Acesso em 4 Jun 2004]. Disponível em: URL: http://portalweb02. saude.gov.br/saude/ visualizar_texto.cfm? idtxt $=17098$

23. Ciolac EG, Guimarães GV. Exercício físico e síndrome metabólica. Rev Bras Med Esporte 2004;10(4):319-24.

24. Guedes DP, Guedes JERP. Controle do peso corporal: composição corporal, atividade física e nutrição. 2. ed. Rio de Janeiro: Shape; 2003. 327 p.

25. Barros SSH. Padrão de prática de atividades físicas de crianças em idade pré-escolar. São Paulo. Dissertação . [ Mestrado em Educação física].-Universidade Federal de Santa Catarina; 2005, 95p.

26. Blair SN, Connelly JC. How much physical activity should we do? The case for moderate amounts of intensities of physical activity. Res Q Exerc Sport. 1996;67(2):193-205.

27. Sebastião E, et al. Atividade física e doenças crônicas em idosos de Rio Claro,SP. Rev. Educ Física 2008;14(4):381-8.

28. Siqueira FV, et al. Atividade física em adultos e idosos residentes em áreas de abrangência de unidades básicas de saúde de municípios das regiões Sul e Nordeste do Brasil. Cad Saúd Pública 2008; 24(1):39-54.

29. Malta DC, et al. A construção da vigilância e prevenção das doenças crônicas não transmissíveis no contexto do Sistema Único de Saúde. Epidemiol. Serv Saúde 2006;15(3):47-65.

30. Braga C, Lautert L. Caracterização sociodemográfica dos idosos de uma comunidade de Porto Alegre. Rev Gaúcha Enferm 2004;25(1):44-55.

31. Monteiro CA, Conde WL, Popkin BM. Independent effects of income and education of the risk obesity in Brazilian adult population. J Nutr. 2001;131:881-6.

32. Fratiglioni L, De Ronchi D, Aguero, Torres H. Worldwide prevalence and incidence of dementia. Drugs Aging 1999; 15(3): 365-75.

33. Farrer LA, et al. Effects of age, sex and ethnicity on the association between apolipoprotein $\mathrm{E}$ genotype and Alzheimer disease: a metaanalysis. JAMA 1997;278(16):1349-56.

34. Lautenschlager NT, et al. Risk of dementia among relatives of Alzheimer's disease patients in the MIRAGE study: what is in store for the oldest old? Neurology 1996;46(3):641-50.

35. Jorm AF, Jolly D. The incidence of dementia: a meta-analysis. Neurology. 1998;51:728-33. 
36. Hendrie $\mathrm{HC}$, et al. Incidence of dementia and Alzheimer disease in 2 communities: Yoruba residing in Ibadan, Nigeria, and African Americans residing in Indianapolis, Indiana. JAMA 2001;285:739-47.

37. Bertram L, et al. Systematic meta-analyses of Alzheimer disease genetic association studies: the AlzGene database. Nat Genet 2007;39:17-23.

38. Hagberg MJ, Wilund RK, Ferrell ER. Apo E gene and gene-environment effects on plasma lipoprotein-lipid levels. Physiol Genomics. 2000; 4:101-8.

39. Hallman DM, et al. The apolipoprotein E polymorphism: a comparison of allele frequencies and effects in nine populations. Am J Hum Genet 1991; 49:338-49.

40. Sandholzer C, et al. High frequency of the apo e allele in Khoi San from South Africa. Hum Genet 1995; 95: 46-8.

41. Gerdes LU, et al. The apolipoprotein E polymorphism in Greenland Inuit in its global perspective. Hum Genet 1996; 98: 546-50.

42. Andrade FM, et al. High heterogeneity of apolipoprotein E gene frequencies in South American Indians. Ann Hum Biol 2000; 27(1): 29-4.

43. Demarchi DA, et al. APOE polymorphism distribution among Native Americans and related populations. Ann Hum Biol 2005; 32(3): 351-65.

44. Asakawa J, et al. Two-dimensional gel studies of genetic variation in the plasma protein of Amerindians and Japanese. Hum Genet 1985; 50(3):222-30.

45. Marin GB, et al. Absence of the E2 allele of apolipoprotein $\mathrm{E}$ in Amerindians. Rev Bras Genet 1997; 20:741-3.

46. Utermann G, Pruin N, Steinmetz A. Polymorphim of apolipoprotein E. III Effect of a single polymorphic gene locus on plasma lipid levels in man. Clin Genet 1979; 15(1): 63-2.

47. Gottlieb MGV, et al. Association between the Arg polymorphism of the leptin receptor and metabolic syndrome in free-living community elderly. Metab Syndr Relat Disord 2009;74(4):341-8.

48. Gottlieb MGV, et al. Association among oxidized LDL levels, MnSOD, apolipoprotein E polymorphisms, and cardiovascular risk factors in a south brazilian region population. Genet Mol Res 2005;30(4):691-03.
49. Schwanke CHA, et al. Análise da Associação entre Polimorfismo do Gene da Apolipoproteína E e Fatores de Risco Cardiovasculares em Idosos Longevos.Arq Bras Cardiol 2002;78(6):561-70.

50. Sivieiro J. Construção de uma avaliação nutricional global de idosos socialmente ativos do município de Gravataí. Porto Alegre. Dissertação [Mestrado] - UFPA; 2002.131p.

51. Word Health Organization. Diet, nutrition and the prevention of chronic diseases. Geneva: WHO;1990.

52. Da Cruz IBM, Moriguchi EH. Projeto Veranopolis : reflexões sobre envelhecimento bem sucedido. Porto Alegre:Oficina da Longevidade;2002. p.138.

53. World Health Organization. The world health report 2002. Genebra: World Health Organization; 2002.

54. Siviero J, et al. Aspectos relacionados ao hábito alimentar e estilo de vida de idosos acima de 80 anos e de seus familiares cuidadores em Veranópolis, RS. Rev Med.PUCRS 2002;12(4):342-50.

55. Almeida MSC. Avaliação dos critérios de obesidade em idosos com mais de 80 anos: relação entre fatores de risco coronariano.Porto Alegre. Dissertação [ Mestrado em Enfermagem]. -Pontifícia Universidade Católica do Rio Grande do Sul;1997.

56. Steck SE, et al. Cooked meat and risk of breast cancer lifetime versus recent dietary intake. Epidemiol 2007;18(3):73-382.

57. Steinmetz KA, Potter JD. Vegetables, fruit, and cancer prevention: a review. J Am Diet Assoc 1996;96(10):1027-39.

58. Governo do Estado de São Paulo; Secretaria de Estado da Saúde. Coordenadoria de Controle de Doenças;Centro de Vigilância. Prevenção de Doenças Crônicas não transmissíveis (DCNT) e de seus fatores de risco: guia básico para agentes de saúde. 3. ed. São Paulo: CVE; 2008. 40p.

59. Pena SDJ. Genetic variation and structure of brasilian population in relation to genetic diseases: international conference on nutrigenomics. Washington :Program and Abstract Book; 2010.

60. Agência Nacional de Saúde Suplementar (Brasil). Panorama das ações de promoção da saúde e prevenção de riscos e doenças na saúde suplementar : Agência Nacional de Saúde Suplementar. Rio de Janeiro: ANS: 2008. 88 p. 